\title{
BMJ Open Caesarean sections and the prevalence of preterm and early-term births in Brazil: secondary analyses of national birth registration
}

\author{
Fernando C Barros, ${ }^{1}$ Dacio de Lyra Rabello Neto, ${ }^{2}$ Jose Villar, ${ }^{3,4}$ \\ Stephen H Kennedy, ${ }^{3,4}$ Mariangela F Silveira, ${ }^{5}$ Jose Luis Diaz-Rossello, ${ }^{6}$ \\ Cesar G Victora ${ }^{5}$
}

To cite: Barros FC, Rabello Neto DdL, Villar J, et al. Caesarean sections and the prevalence of preterm and early-term births in Brazil: secondary analyses of national birth registration. BMJ Open 2018;8:e021538. doi:10.1136/ bmjopen-2018-021538

- Prepublication history for this paper is available online. To view these files please visit the journal online (http://dx.doi. org/10.1136/bmjopen-2018021538).

Received 6 January 2018 Revised 10 July 2018 Accepted 13 July 2018
Check for updates

(C) Author(s) (or their employer(s)) 2018. Re-use permitted under CC BY-NC. No commercial re-use. See rights and permissions. Published by BMJ.

For numbered affiliations see end of article.

Correspondence to Dr Fernando C Barros; fcbarros.epi@gmail.com

\section{ABSTRACT}

Objectives To investigate whether the high rates of caesarean sections (CSs) in Brazil have impacted on the prevalence of preterm and early-term births.

Design Individual-level, cross-sectional analyses of a national database.

Setting All hospital births occurring in the country in 2015.

Participants 2903716 hospital-delivered singletons in 3157 municipalities, representing $>96 \%$ of the country's births.

Primary and secondary outcome measures CS rates and gestational age distribution (<37, 37-38, 39-41 and 42 or more weeks' gestation). Outcomes were analysed according to maternal education, measured in years of schooling and municipal CS rates. Analyses were also adjusted for maternal age, marital status and parity. Results Prevalence of CS was $55.5 \%$, preterm prevalence ( $<37$ weeks' gestation) was $10.1 \%$ and early-term births (37-38 weeks of gestation) represented $29.8 \%$ of all births, ranging from $24.9 \%$ among women with $<4$ years of schooling to $39.8 \%$ among those with $>12$ years of education. The adjusted prevalence ratios of preterm and early-term birth were, respectively, 1.215 (1.174-1.257) and 1.643 (1.616-1.671) higher in municipalities with $\geq 80 \%$ CS compared with those $<30 \%$.

Conclusions Brazil faces three inter-related epidemics: a CS epidemic; an epidemic of early-term births, associated with the high CS rates; and an epidemic of preterm birth, also associated with CS but mostly linked to povertyrelated risk factors. The high rates of preterm and earlyterm births produce an excess of newborns at higher risk of short-term morbidity and mortality, as well as long-term developmental problems. Compared with high-income countries, there is an annual excess of 354000 preterm and early-term births in Brazil.

\section{INTRODUCTION}

WHO in a recent statement reaffirms that caesarean sections (CSs) up to $15 \%$ are associated with lower maternal and neonatal mortality, but CS rates above this level are no longer associated with reduced mortality. ${ }^{1}$ In
Strengths and limitations of this study

- Analysis of a national database of 2.9 million singleton live births, representing $>96 \%$ of all births occurring in Brazil in 2015, a country where $<2 \%$ of births occur at home.

- Gestational ages are assessed routinely, according to recommendations of the Ministry of Health, and available for $97.5 \%$ of the births.

- Individual-level analyses were carried out; to minimise residual confounding, we studied gestational age according to prevalence of caesarean sections (CSs) at municipal level.

- We used Poisson regression with robust variance to estimate crude and confounder-adjusted prevalence ratios of preterm and early-term births according to municipal CS rates.

- One limitation of the database was the lack of information on indications for CSs, but information was available on whether the CS took place before the onset of labour.

Brazil, starting in the 1970s, CS rates increased rapidly, and since 2009 these represent over half of all deliveries in the country. ${ }^{2}$ In a recent review, Brazil had the second highest rate in the world (55.6\% in 2012), just below the Dominican Republic (56.4\% in 2013). ${ }^{3}$ CS rates in the different regions of the world range from $3.0 \%$ in West Africa to $40.5 \%$ in Latin America and the Caribbean. ${ }^{3}$ Brazil is also undergoing an epidemic of preterm births, ${ }^{4}$ and although some of these births could represent medically indicated preterm deliveries (eg, to avoid maternal or fetal mortality), part of this epidemic has been attributed to scheduled CS, frequently due to doctor and/or maternal convenience. ${ }^{5-9}$

Most scheduled CS operations are conducted on affluent women who deliver in private care or through private health insurance plans. Because of imprecise gestational 
age estimation, they affect the prevalence of late preterm births (34-36 weeks' gestation). ${ }^{10}$ In this paper, we hypothesised that, from a public health perspective, the most important consequence of scheduled CS deliveries-in terms of the number of births affected-would not be the increase in preterm deliveries, but the shift of full and late term (39-41 weeks' gestation) births to the early-term (37-38 weeks' gestation) period. Babies born between 39 $0 / 7$ weeks and $416 / 7$ weeks are considered full term and late term, ${ }^{11}$ and this is the gestational age group with the lowest levels of morbidity and mortality. ${ }^{12} 13$

It is well known that preterm babies are at increased risk of mortality and long-term sequelae. ${ }^{14}$ Early-term infants are also at higher risk of mortality, ${ }^{12}{ }^{15-17}$ including postneonatal sudden unexpected infant deaths. ${ }^{18}$ Early-term delivery has also been linked to permanent educational and cognitive impairment. In Belarus, among children aged 6.5 years, the mean IQ of those born at 37 weeks was significantly lower than that of those born at 39-41 weeks' gestation. ${ }^{19}$ Swedish adults, aged $23-29$ years, who were born at 37-38 weeks' gestation had higher levels of disability-defined by receiving sickness pension, handicap allowance and/or disability assistance-compared with those born at 39-41 weeks. ${ }^{20}$ In Scotland, where deliveries between 37 and 39 weeks' gestation are 7 times more frequent than preterm births $(37.3 \%$ and $5.2 \%$, respectively), the former account for more cases of special education needs at school age than the latter. ${ }^{13}$

The main objective of this study was to analyse whether the high rates of CS, and especially prelabour CS, were affecting the gestational age distribution in Brazil, by analysing 2.9 million births reported to the National Live Births Information System (SINASC) in 2015. The analyses were restricted to singleton births to allow for international comparisons. ${ }^{21} 22$

\section{METHODS}

This is a cross-sectional analysis using the 2015 SINASC national database which has provided information on 2903716 hospital singleton deliveries, corresponding to $>96 \%$ of the country births. For all live births taking place in health facilities, the staff must fill a birth certificate, and this information is forwarded to the Ministry of Health and entered into the SINASC. Multiple births (62 927) were excluded from the analyses, as well as 46826 births that occurred outside health facilities.

The official live birth report forms include data on the following variables: maternal age in years (coded as $<20$, 20-34, 35+ years), parity (number of previous births: $0,1,2+$ ), marital status (single or living with partner), education in completed years of schooling $(0-4,5-8$, $9-12,>12$ ), previous CS (collected only from parous women: yes or no), type of delivery (vaginal or CS) and for CS delivery, whether it was performed before or after the onset of labour. Gestational age is assessed following the Ministry of Health recommendations, by the date of the last menstrual period (LMP) ${ }^{23}$ In cases where the
LMP is unknown or inconsistent, the best obstetric estimate is then used, comprising either ultrasonographic evaluation or physical examination of the newborn. Gestational age was recorded in full weeks for $97.5 \%$ of the births; in $55.9 \%$ of the deliveries by the LMP, by physical examination methods in $18.1 \%$, and by ultrasonographic assessment in $15.8 \%$; for $10.2 \%$ of deliveries, the method was not specified. Gestational age in weeks was grouped as $<37,37-38,39-41$ and $42+$ weeks. The proportions of missing values ranged from $0.1 \%$ to $8.5 \%$ (table 1 ); these were excluded from the analyses.

All analyses were carried out at individual level. Initially, we estimated the prevalence of CS and preterm births according to maternal education levels, with singleton births as the unit of analysis. We then reported on the gestational age distribution for strata of municipalities grouped according to levels of CS rates. We adopted this second approach to account for the fact that a certain proportion of CSs is medically indicated, including some procedures that will result in preterm deliveries, as is the case for early interruption of pregnancy due to maternal or fetal conditions. ${ }^{24}$ These are still individual-level analyses, but the main explanatory variable is the CS rate in a municipality, not whether or not each pregnancy resulted in a CS. For example, if a municipality has CS rates of $60 \%$ or higher, most likely a high proportion of these operations will not be medically indicated. ${ }^{1}$ Therefore, we can assess the role of CS in affecting gestational age in a more reliable way than analysing individual pregnancies for which a medical indication may or may not be present. This is the rationale for our analyses including the 520 municipalities with more than 1000 live births in 2015 .

For this analysis, we selected-from the 3157 municipalities that reported births to SINASC in 2015-the 520 municipalities with more than 1000 births. These included $82.4 \%$ of all births in the country, and because of the large number of births per municipality, provided stable estimates of CS rates, there is also evidence that data quality is better in large than in small municipalities. ${ }^{25}$ The 520 municipalities were divided into seven categories of CSs $(<30 \%, 30 \%-39.9 \%, 40 \%-49.9 \%, 50 \%-59.9 \%$, $60 \%-69.9 \%, 70 \%-79.9 \%$ and $\geq 80 \%)$. Municipal CS rates ranged from $12.4 \%$ to $98.8 \%$, and 28 municipalities had CS rates $\geq 80 \%, 39 \mathrm{had}<30 \%$ and the remaining categories ranged from 54 to 118 municipalities. Among the 2367 municipalities with less than 1000 births which were not included in this analysis, 1270 reported less than 100 births. In this group of municipalities, the prevalence of CS and preterm birth was $53.5 \%$ and $8.5 \%$, respectively.

$\mathrm{X}^{2}$ tests were used to evaluate differences between proportions presented in the figures, and Poisson regression with robust variance was used to analyse the association between preterm and early-term births and CSs in crude analyses and after adjusting for confounders. Poisson regression was chosen, instead of logistic regression, because it provides prevalence ratios which are more interpretable and easier to communicate to non-specialists than ORs. ${ }^{26}$ The confounding variables included maternal schooling, age, 
Table 1 Demographic, socioeconomic and healthcare characteristics of mothers and newborns, and number and proportion of municipalities with more than 1000 births/year according to CS rates, Brazil 2015

\begin{tabular}{|c|c|c|c|}
\hline & Number & $\%$ & $95 \% \mathrm{Cl}$ \\
\hline \multicolumn{4}{|l|}{ Maternal age (years) } \\
\hline$<20$ & 530738 & 18.27 & 18.23 to 18.32 \\
\hline 20-34 & 2003173 & 68.98 & 68.93 to 69.04 \\
\hline $35+$ & 369779 & 12.73 & 12.70 to 12.77 \\
\hline \multicolumn{4}{|l|}{ Parity } \\
\hline 0 & 1059025 & 38.74 & 38.70 to 38.81 \\
\hline 1 & 851412 & 31.14 & 31.10 to 31.21 \\
\hline $2+$ & 823032 & 30.1 & 30.07 to 30.17 \\
\hline \multicolumn{4}{|c|}{ Maternal schooling (years) } \\
\hline $0-4$ & 162684 & 5.73 & 5.71 to 5.76 \\
\hline $8-5$ & 738477 & 26.02 & 25.97 to 26.07 \\
\hline $12-9$ & 1408778 & 49.64 & 49.58 to 49.70 \\
\hline$>12$ & 527917 & 18.6 & 18.56 to 18.65 \\
\hline \multicolumn{4}{|l|}{ Marital status } \\
\hline Single & 1242332 & 43.23 & 43.18 to 43.29 \\
\hline Living with partner & 1631058 & 56.76 & 56.71 to 56.82 \\
\hline \multicolumn{4}{|c|}{ Mode of delivery } \\
\hline Vaginal & 1289890 & 45.45 & 44.40 to 44.51 \\
\hline Caesarean section & 1611788 & 55.54 & 55.49 to 55.60 \\
\hline
\end{tabular}

Previous caesarean

section*

\begin{tabular}{|c|c|c|c|}
\hline No & 881186 & 55.17 & 55.10 to 55.25 \\
\hline Yes & 716548 & 44.82 & 44.79 to 44.94 \\
\hline \multicolumn{4}{|c|}{ Gestational age (weeks) } \\
\hline$<37$ & 286204 & 10.11 & 10.07 to 10.14 \\
\hline $37-38$ & 844472 & 29.82 & 29.77 to 29.88 \\
\hline $39-41$ & 1612186 & 56.93 & 56.88 to 57.00 \\
\hline $42+$ & 88633 & 3.13 & 3.11 to 3.15 \\
\hline \multicolumn{4}{|l|}{ Birth weight (g) } \\
\hline$<2500$ & 210414 & 7.25 & 7.22 to 7.28 \\
\hline $2500-2999$ & 658628 & 22.7 & 22.65 to 22.75 \\
\hline 3000-3999 & 1881010 & 64.83 & 64.78 to 64.89 \\
\hline $4000+$ & 151355 & 5.21 & 5.19 to 5.24 \\
\hline All & 2903716 & 100 & \\
\hline $\begin{array}{l}\text { Municipalities <30\% } \\
\text { CS }\end{array}$ & 39 & 7.5 & 5.5 to 10.1 \\
\hline $\begin{array}{l}\text { Municipalities 30\%- } \\
\text { 39.9\% CS }\end{array}$ & 54 & 10.4 & 8.1 to 13.3 \\
\hline $\begin{array}{l}\text { Municipalities } 40 \%- \\
\text { 49.9\% CS }\end{array}$ & 94 & 18.1 & 15.0 to 21.6 \\
\hline $\begin{array}{l}\text { Municipalities 50\%- } \\
59.9 \% \text { CS }\end{array}$ & 113 & 21.7 & 18.4 to 25.4 \\
\hline $\begin{array}{l}\text { Municipalities 60\%- } \\
69.9 \% \text { CS }\end{array}$ & 118 & 22.7 & 19.3 to 26.4 \\
\hline
\end{tabular}

Continued
Table 1 Continued

\begin{tabular}{lrrl}
\hline & Number & $\%$ & $95 \%$ Cl \\
\hline $\begin{array}{l}\text { Municipalities } 70 \%- \\
79.9 \% \text { CS }\end{array}$ & 74 & 14.2 & 11.5 to 27.5 \\
$\begin{array}{l}\text { Municipalities } \\
\geq 80 \% \text { CS }\end{array}$ & 28 & 5.4 & 3.8 to 7.7 \\
All municipalities & 520 & 100 & \\
\hline
\end{tabular}

Missing cases: maternal age $(0.1 \%)$, parity $(5.9 \%)$, maternal schooling $(2.3 \%)$, marital status $(2.1 \%)$, mode of delivery $(0.1 \%)$, previous CS $(8.5 \%)$, gestational age $(2.5 \%)$, birth weight $(0.1 \%)$. *Only parous women were included.

CS, caesarean section.

parity and marital status. Two outcomes were used: preterm birth ( $<37$ weeks vs $37+$ weeks) and early-term births (37-38 weeks vs $\geq 39$ weeks). Preterm births were excluded from the second set of analyses.

The outcomes in the municipal-based analyses were preterm and early-term births. The proportion of medicallyindicated CS births $<34$ weeks is high, having increased $36 \%$ between 1996 and 2006 in the USA. ${ }^{27}$ However, as presumably such births should not be affected by elective, non-medically indicated CSs (as obstetricians would not err by several weeks when estimating gestational age), we also examined $<34$ weeks births in the analyses of municipalities. If municipal CS rates are not associated with the prevalence of $<34$ weeks births, this finding will support the hypothesis that CS without medical indication are solely affecting the prevalence of preterm (34-36 weeks) and early-term births.

The differences between the observed number of births in each gestational age group and the number that would be expected, had our distribution been similar to that observed in 34 high-income countries, ${ }^{28}$ were calculated.

The study was based on secondary, publicly available data sources; all information was anonymised.

\section{Patient and public involvement}

The development of the research questions and outcome measures has been indirectly influenced by patients' priorities, experience and preference, in the measure that we are dealing with CSs that are frequently decided by the patients themselves.

Patients were not involved in the design or in the recruitment of the study, since the analysed information was obtained from a public national database.

We hope and will do our best to ensure that the results of this study will reach the general population, through the media and institutions like the Ministry of Health.

This is not a randomised trial; patients and public have not been involved.

\section{RESULTS}

Table 1 describes the demographic, socioeconomic and healthcare characteristics of the over 2.9 million mothers and singleton newborns analysed in this paper. 


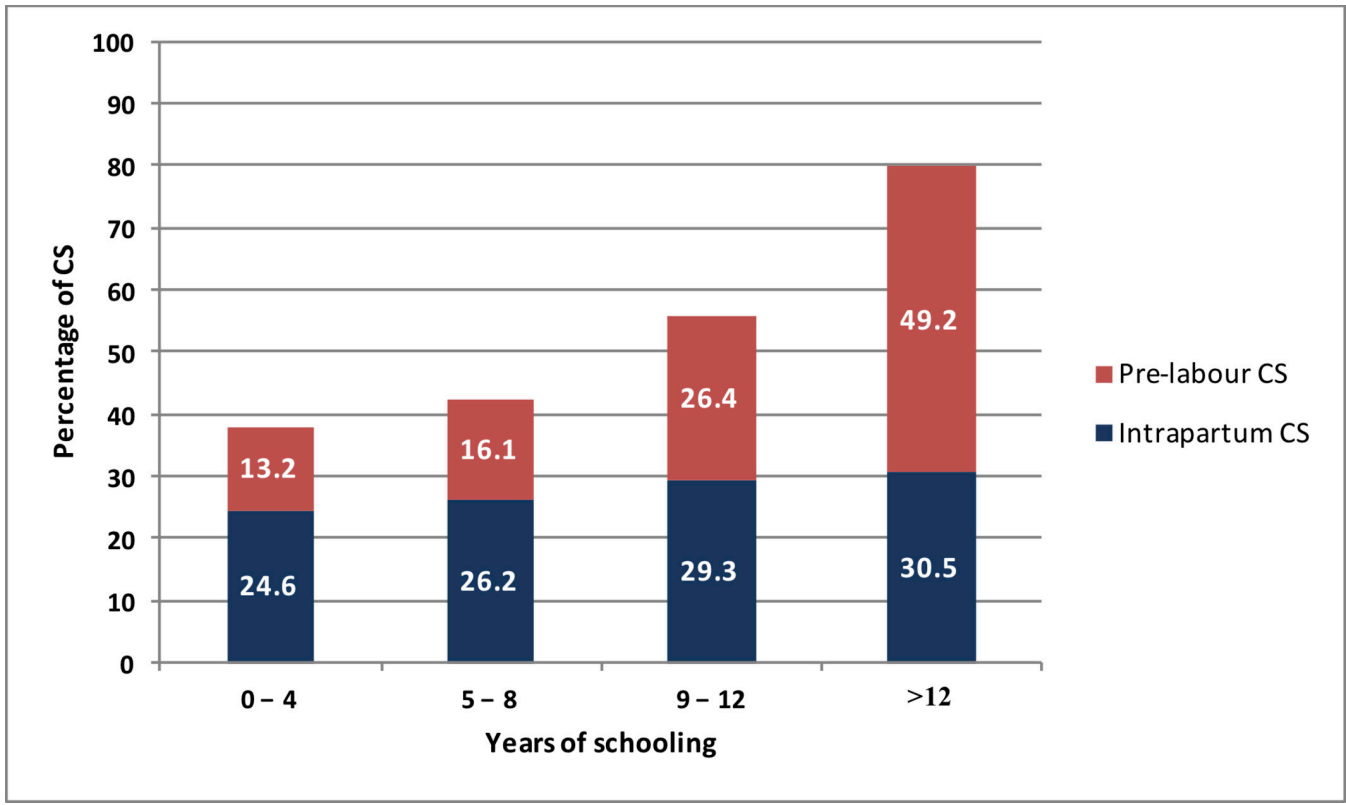

Figure 1 Prevalence of intrapartum and prelabour caesarean sections (CSs) according to maternal education ( $\mathrm{n}=2903$ 716 singleton births), Brazil 2015.

Adolescents represented $18.3 \%$ of the study population, $38.7 \%$ of the women were nulliparous, and among those who had at least one previous birth, $44.8 \%$ reported a previous CS. The prevalence of previous CS for all women, including primiparae, was $27.2 \%$. Table 1 also presents the numbers and proportions of the seven groups of municipalities with more than 1000 births per years stratified by CS rates, from less than $30 \%$ to $\geq 80 \%$.

In 2015, CS represented $55.5 \%$ of all births in the country, with $48 \%$ of these operations taking place before labour started. CS prevalence ranged from $37.8 \%$ among women with $0-4$ years of schooling to $79.7 \%$ among those with $>12$ years (figure 1). Vaginal deliveries, therefore, accounted for $62.2 \%$ of the births in the lowest schooling group, but only 20.3\% among mothers of the highest educated category. Although the prevalence of intrapartum CS augmented slightly with schooling, the largest gradient was for prelabour CS which ranged from 13.2\% to $49.2 \%$ in the extreme groups of schooling (figure 1).

Gestational age was reported for $97.5 \%$ of all births in SINASC. The prevalence of preterm birth was $10.1 \%$, declining slightly from $12.2 \%$ in mothers with $0-4$ years of schooling to $9.3 \%$ among those with $>12$ years (figure 2 ). The overall prevalence of preterm births following vaginal births was $7.6 \%$ in the least educated groupwhere vaginal deliveries represented $62 \%$ of all birthsand declined to only $1.9 \%$ among women with $>12$ years-where vaginal deliveries accounted for $20 \%$ of all

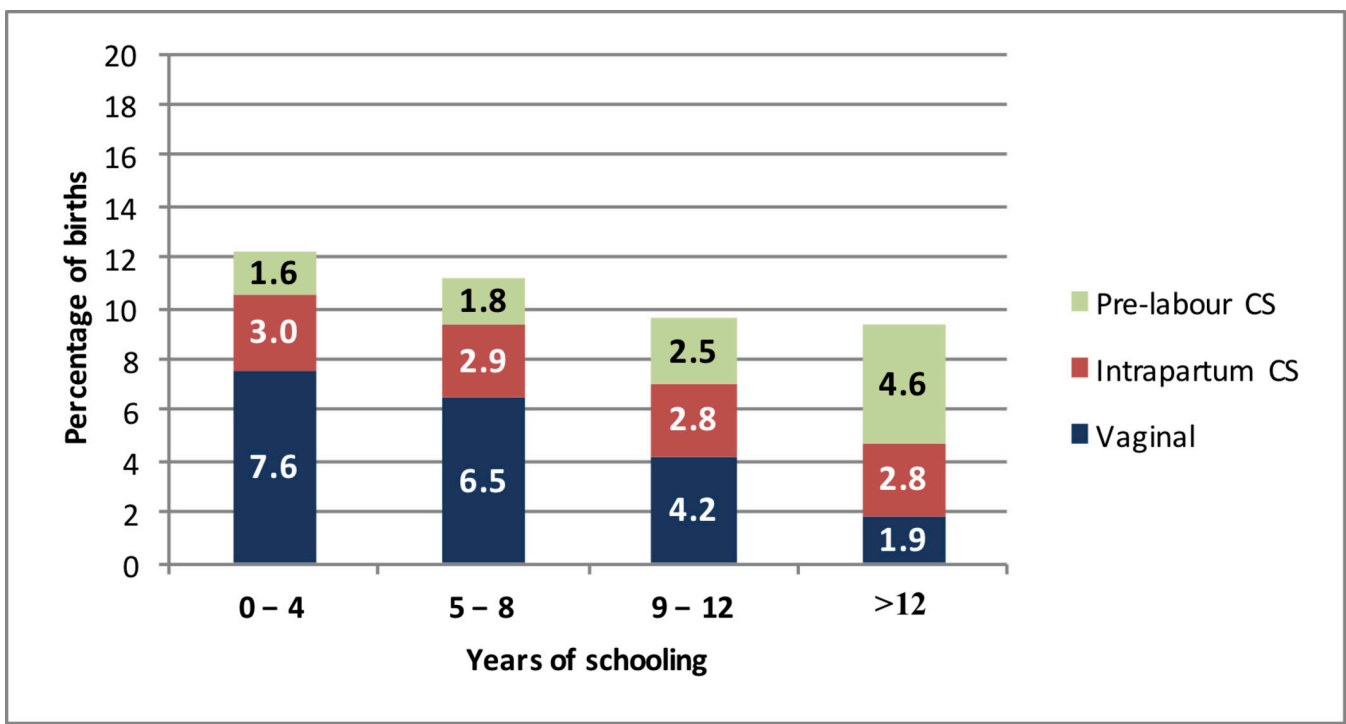

Figure 2 Prevalence of preterm births after vaginal delivery and caesarean sections (CSs) (prelabour or intrapartum), according to maternal education ( $n=2903716$ singleton births), Brazil 2015. 


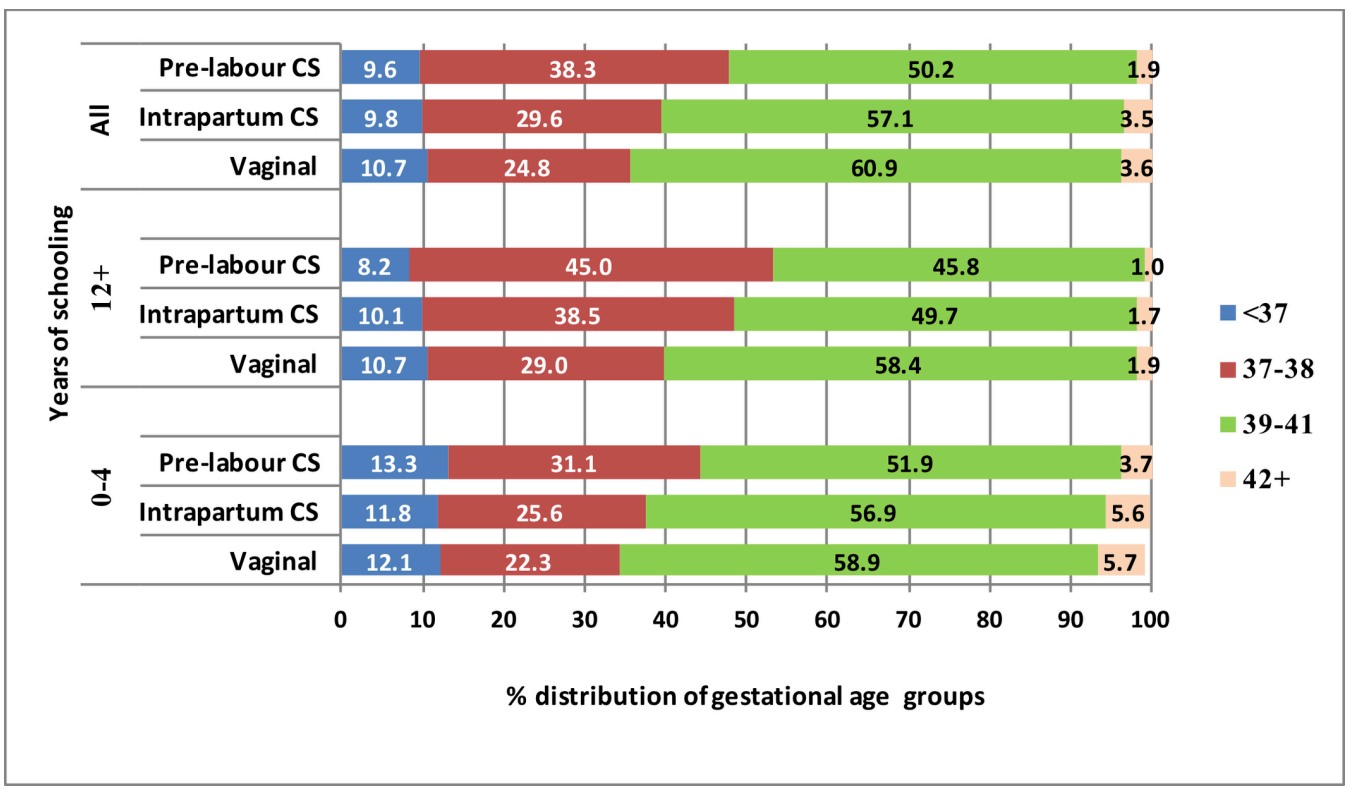

Figure 3 Gestational age distribution for births of women with low ( $0-4$ years) and high ( $>12$ years) schooling and for the whole population, according to the type of delivery (vaginal, intrapartum CS and prelabour CS) ( $n=2903716$ singleton births), Brazil 2015. CS, caesarean section.

births. In contrast, prelabour CSs represented $16 \%$ of all preterm births among the less- educated mothers and $50 \%$ in the more- educated group. Therefore, although the prevalence of preterm birth varied slightly by education, there were marked differences regarding the type of delivery within each educational category.

In addition to the $10.1 \%$ preterm deliveries, $29.8 \%$ of all births in Brazil took place at 37-38 weeks' gestation, $56.9 \%$ between 39 and 41 weeks, and $3.1 \%$ at 42 or more weeks. In contrast to preterm deliveries, early-term births were substantially more common among women with $>12$ years of education $(39.8 \%)$ compared with those with $<4$ years $(24.9 \% ; \mathrm{p}<0.001)$.

Preterm prevalence differed slightly among vaginal and CS deliveries (figure 3), but early-term births varied markedly: $24.8 \%$ in vaginal deliveries, $29.6 \%$ in intrapartum CSs and $38.3 \%$ in prelabour CSs. Conversely, the prevalence of term births was $60.9 \%$ in vaginal deliveries and $50.2 \%$ in prelabour CSs. Differences were most marked among more-educated women, with early-term births accounting for $29 \%$ of vaginal deliveries and $45 \%$ of prelabour CSs.

Poisson regression analyses were conducted using preterm and early-term birth as outcomes and type of delivery (vaginal or CS) as exposure. For preterm birth, in the unadjusted analysis the prevalence ratio of preterm birth in CS deliveries was 0.907 (0.900 to 0.913, $\mathrm{p}=0.0001$ ), and after adjusting for maternal schooling, age, parity and marital status the prevalence ratio was 0.957 $(0.950$ to $0.964, p=0.0001)$. The corresponding values for the analyses of early-term birth as outcome were 1.349 (1.344 to $1.354 ; \mathrm{p}=0.0001$ ) and 1.247 (1.242 to 1.252 , $\mathrm{p}=0.0001$ ), respectively, for unadjusted and adjusted analyses.
We then proceeded to the analyses of the association of gestational age distribution according to the CS rates in the municipalities where the women gave birth. Figure 4 shows that preterm prevalence is $9.3 \%$ in the group of municipalities with the lowest CS rates $(<30 \%)$ and slightly higher in the remaining municipalities. Early-term births were markedly less frequent $(21.7 \%)$ in municipalities with $<30 \%$ CSs compared with those with $\geq 80 \%$ CS rates (40.4\%) - a difference of 18.7 percent points. Conversely, the prevalence of births between 39 and 41 weeks lowered from $63.5 \%$ to $47.2 \%$, and the proportion of births at $42+$ weeks was $5.5 \%$ and $1.8 \%$, respectively. All linear trends were highly significant $(\mathrm{p}<0.001)$.

We have also analysed the rates of births $<34$ weeks for the different municipality groups, as, presumably, these rates should not be associated with CS rates. The results did not show any clear pattern between municipalities. For the seven groups of municipalities shown in figure 4, from bottom to top, the rates were $2.4 \%, 2.7 \%, 2.8 \%$, $2.9 \%, 3.1 \%, 2.7 \%$ and $2.6 \%$, respectively.

Women living in municipalities with high CS rates tended to have higher educational levels than those of low CS rate municipalities-the group with 0-4 years of schooling represented $10.2 \%$ in municipalities with $<30 \%$ CSs but only $3.7 \%$ in those with $\geq 80 \%$ prevalence, while women with $>12$ years of schooling accounted for $4.6 \%$ and $21.6 \%$, respectively. High CS municipalities also had lower prevalence of adolescents, single women and multiparae among their mothers. These variables were also associated with preterm and early-term births, and we used Poisson regression to produce unadjusted and adjusted analyses of the association between preterm and early-term births and municipalities with different CS rates, taking into account these confounders. The units of 


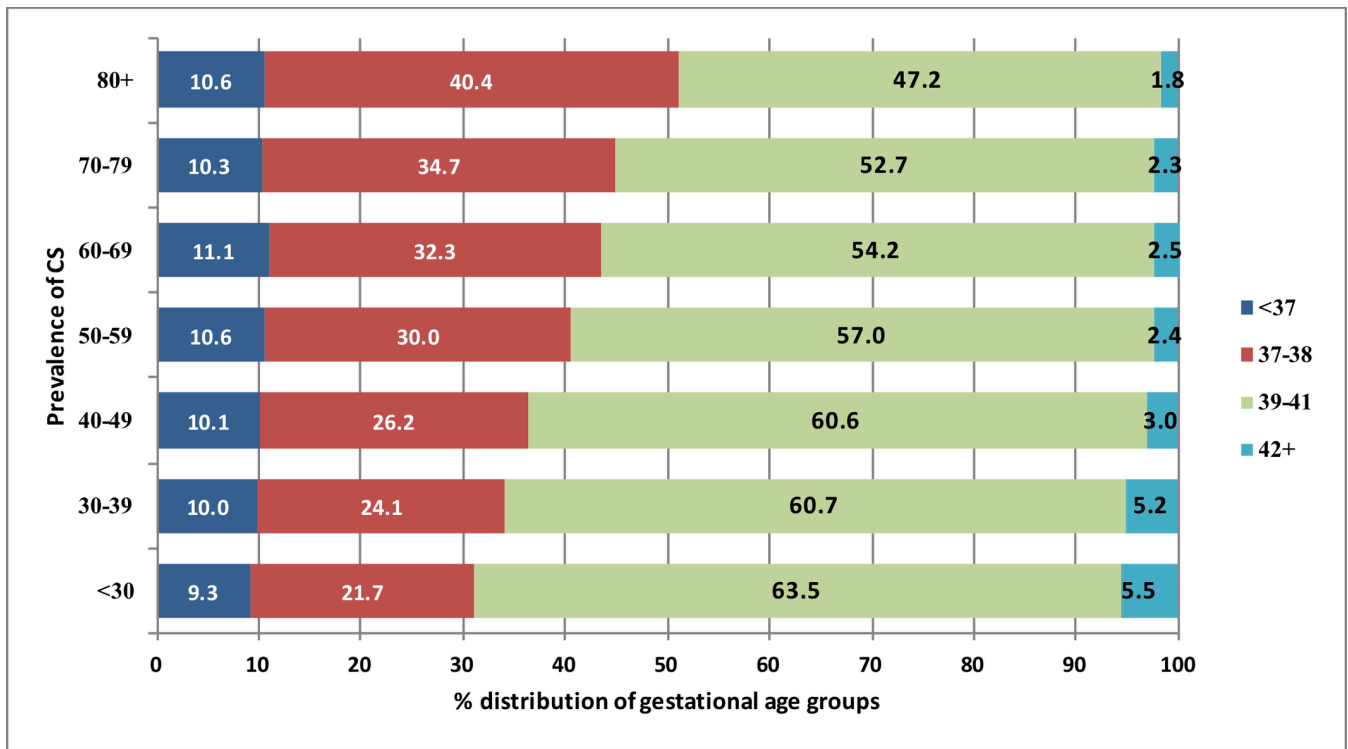

Figure 4 Gestational age distribution according to different rates of caesarean sections (CSs) in 520 municipalities with more than 1000 births per year, Brazil 2015.

analyses were individual women, according to municipal rates of $\mathrm{CS}$.

Table 2 shows the results of these analyses, using municipalities with $<30 \% \mathrm{CSs}$ as the reference group. With preterm birth as outcome, the crude prevalence ratios showed growing trends-in municipalities with 30\%-39\% of CS rates, the ratio was 1.076 while for municipalities with $\geq 80 \%$ of CS, this was 1.145 . After adjustment for confounders, these ratios were 1.090 and 1.215 , respectively. When the outcome variable was gestational age 37-38 weeks, unadjusted prevalence ratios ranged from 1.120 for municipalities with $30 \%-39 \%$ of CS to 1.890 for municipalities with $\geq 80 \%$ of CS. After adjusting for confounders, the ratios varied from 1.043 for municipalities with $30 \%-39 \%$ CS to 1.643 for those with rates $\geq 80 \%$.

Finally, we took the current numbers of annual births with $<37,37-38$ and 39 weeks or more in 2015 and calculated the expected numbers based on the gestational age distribution of 34 high-income countries. In these countries, the median values were of $5.5 \%$ for $<37$ weeks and of $22.2 \%$ for $37-38$ gestational weeks, ${ }^{28}$ compared with our current results of $10.1 \%$ and $29.8 \%$, respectively. Brazil would have had 133571 fewer preterm births and 220682 fewer early-term births had the gestational age distribution been the same as in high-income countries, and consequently an additional 354253 babies born at 39 or more weeks.

\section{DISCUSSION}

Our results show that the wide differences in CS prevalence among different socioeconomic groups are due to the markedly higher prevalence of prelabour CS in more-educated women. We used maternal education, measured by years of schooling, as a proxy for socioeconomic position. ${ }^{29}$ In women with more than 12 years of

Table 2 Poisson regression analyses of preterm and early-term births according to municipal CS rates, Brazil 2015

\begin{tabular}{|c|c|c|c|c|c|c|c|c|}
\hline \multirow{3}{*}{$\begin{array}{l}\text { Municipal CS } \\
\text { prevalence } \\
\text { rates }\end{array}$} & \multicolumn{4}{|c|}{ Preterm births } & \multicolumn{4}{|c|}{ Early-term births } \\
\hline & \multicolumn{2}{|c|}{ Crude analyses } & \multicolumn{2}{|c|}{ Adjusted analyses* } & \multicolumn{2}{|c|}{ Crude analyses } & \multicolumn{2}{|c|}{ Adjusted analyses * } \\
\hline & $\begin{array}{l}\text { Prevalence } \\
\text { ratio }\end{array}$ & $95 \% \mathrm{Cl}$ & $\begin{array}{l}\text { Prevalence } \\
\text { ratio }\end{array}$ & $95 \% \mathrm{Cl}$ & $\begin{array}{l}\text { Prevalence } \\
\text { ratio }\end{array}$ & $95 \% \mathrm{Cl}$ & $\begin{array}{l}\text { Prevalence } \\
\text { ratio }\end{array}$ & $95 \% \mathrm{Cl}$ \\
\hline $80 \%$ & 1.145 & 1.108 to 1.184 & 1.215 & 1.174 to 1.257 & 1.89 & 1.859 to 1.921 & 1.643 & 1.616 to 1.671 \\
\hline $70 \%-79 \%$ & 1.115 & 1.087 to 1.143 & 1.174 & 1.143 to 1.205 & 1.615 & 1.593 to 1.639 & 1.398 & 1.378 to 1.419 \\
\hline $40 \%-49 \%$ & 1.095 & 1.069 to 1.122 & 1.136 & 1.108 to 1.165 & 1.22 & 1.203 to 1.238 & 1.113 & 1.097 to 1.129 \\
\hline $30 \%-39 \%$ & 1.076 & 1.047 to 1.105 & 1.09 & 1.060 to 1.122 & 1.12 & 1.102 to 1.138 & 1.043 & 1.026 to 1.060 \\
\hline$<30 \%$ & 1.0 & & 1.0 & & 1.0 & & 1.0 & \\
\hline
\end{tabular}

All $p$ values $<0.0001$.

${ }^{*}$ Adjusted for maternal schooling, maternal age, parity, marital status.

CS, caesarean sections. 
schooling, the prevalence of CSs was nearly $80 \%$, and $62 \%$ of these procedures were conducted before labour started. A recent Brazilian study has also documented important differences in CS rates according to maternal socioeconomic position. ${ }^{30}$

The fact that most births occur by CS, and a large part of these procedures are performed before the onset of labour, suggests that iatrogenic preterm births might occur. However, the remarkably strong positive association between socioeconomic position and CS (figure 1) jointly with the negative association of socioeconomic position and preterm vaginal births (figure 2) leads to a paradoxical finding in the individual analyses, showing an apparently protective effect of CS on preterm births. In fact, in our individual analyses, the prevalence ratio of preterm birth associated with CS was 0.957 , indicating a protective effect of $4.3 \%$. Conceivably, women subjected to more intense medicalisation might be protected from preterm delivery which would explain a protective effect of CS on preterm births in the individual-level analyses. However, these findings might be due to residual confounding and were not confirmed by our municipality-based analyses, where preterm and early-term births were more prevalent in municipalities with higher CS rates.

We were able to estimate that municipalities with higher rates of CS presented higher prevalence ratios of both preterm births, and births between 37 and 38 weeks, in comparison with municipalities with $<30 \%$ CSs (figure 4 ). Municipalities with $\geq 80 \%$ of CSs presented $21.5 \%$ higher ratios of preterm births and $64.3 \%$ higher ratios of early births, compared with municipalities with CS rates $<30 \%$ (table 2). As expected, rates of very preterm births were not affected by the municipal CS rates, given that unnecessary CS would not affect such deliveries.

Our results suggest that Brazil is facing three inter-related epidemics: a CS epidemic, especially among highly educated women; an epidemic of preterm births, partly associated with the high CS but, more importantly, linked to poverty-related risk factors; and lastly, an epidemic of early-term births, directly related to the high CS rate. The third epidemic has not been previously reported. The epidemic of preterm births is confirmed by the growing trends of these births in population-based studies in different areas of the country, ${ }^{4}$ and the excess of such births compared with high-income countries $(5.5 \%){ }^{28}$

CSs accounted for $55.5 \%$ of deliveries, reaching $80 \%$ in more-educated women, confirming the existence of a major epidemic which has already been previously described. ${ }^{7}$ Systematically collected data on the progression of labour and causes of CS were unavailable until recently, when Leal et al published results from a national study involving 266 hospitals. Their analyses were focused on late preterm deliveries associated with elective CS, showing markedly higher rates in private than in public hospitals. ${ }^{10}$ Our findings on the educational gradient in CS are consistent with their results, as private care is the rule for highly educated women in Brazil.
The second epidemic is that of preterm births, ${ }^{4}$ and our results suggest that it has two components. First, preterm births following spontaneous vaginal delivery are highly prevalent among poor, less-educated women. These are likely due to known risk factors, some of them shared with those for early-term births ${ }^{31}$ : previous preterm birth, infections during pregnancy, pre-eclampsia, gestational diabetes, underweight, short stature and smoking. ${ }^{32}$ Their prevention requires measures to address social inequities, and improve both pregnancy care and living standards. ${ }^{33}$ The second component, which primarily affects women of high socioeconomic status, has been attributed to scheduled CS, often due to reasons such as doctor and/or maternal convenience. ${ }^{5-810}$ In support of this hypothesis, we found that prelabour CSs account for half of all preterm births among highly educated women in Brazil (figure 2). Overall, 26\% of all preterm births in Brazil follow prelabour CSs. Our results suggest that prelabour CSs do play a role in the preterm epidemic, as shown by the trend of higher prevalence of preterm births in municipalities with higher CS rates.

As mentioned, previous studies on the consequences of high elective CS rates were focused on preterm delivery and, to a lesser extent, on maternal and newborn morbidity and mortality. ${ }^{5-8} 1034$ In contrast, the early-term epidemic has not been previously documented. We report a national prevalence of $29.8 \%$ of all births, ranging from $21.7 \%$ in municipalities with CS rates $<30 \%$, to $40.4 \%$ for municipalities with rates $\geq 80 \%$. As gestational age information in the SINASC system was imprecise up to $2011,{ }^{35}$ we are unable to document time trends in early-term births for the country. Nevertheless, this information is available in the four Pelotas Birth Cohorts covering the period from 1982 to 2015 . In these datasets, the CS rate increased from $27.7 \%$ in 1982 to $65.1 \%$ in 2015 , while the prevalence of early-term births increased from $22.3 \%$ to $37.1 \%$ in the same period. ${ }^{36}$

Data from 34 high-income countries show that preterm births represent $5.5 \%$ of births while early-term births represent $22.2 \%$ of the total number of births. ${ }^{28}$ We estimate that Brazil had 133571 extra preterm babies and another 220682 extra early-term newborns than would be anticipated had our prevalence been the same as in these countries. Our results suggest that the main impact of the high CS rates has been a shift from term to early term births.

We have previously published outcomes in the first 4 years of age of babies born with different gestational ages in three Pelotas, Southern Brazil birth cohorts. In addition to the well-known poor outcomes for preterm babies, we documented that early-term babies had a $60 \%$ greater risk of infant mortality, compared with babies born between 39 and 41 weeks of gestation. ${ }^{12}$

Therefore, in addition to a short-term higher morbidity and mortality, preterm and early-term newborns place additional demands on society by requiring special education services as they reach school age and present 
higher risks of disability in young adulthood, as shown by the Scottish and Swedish studies. ${ }^{1320}$

One strength of our study is the use of the Live Births Information System (SINASC) of the Brazilian Ministry of Health, with 2.9 million singleton live births, corresponding to $>96 \%$ of all births occurring in 2015, in a middle-income country with 208 million inhabitants where home deliveries represent less than $2 \%$ of all births. ${ }^{37}$ The system has some limitations, including the lack of information on indications for CSs and reliance on routine assessment of gestational age, with date of LMP being the first option, with ultrasonography and physical examination being used in cases when LMP is not known. It is recognised that LMP assessed after birth produces slightly higher prevalence estimates of preterm birth than early ultrasound examinations. ${ }^{38}$ These limitations, however, are unlikely to have affected the present results as they should apply to all municipalities under study.

In all estimates of the prevalence of CS, preterm and early-term births in the country, we used the full population of singleton births for the year 2015 and therefore our calculations of excess numbers of preterm and early-term babies are valid for the whole population. We excluded hospitals with less than 1000 births per year only when municipality-based analyses were carried out (figure 4). As mentioned in the Methods section, the reason for this exclusion was that the quality of information in small health units is less reliable. ${ }^{25}$ These hospitals were responsible for $20.3 \%$ of the country's births, of which $53.5 \%$ were CS; the prevalence of preterm and early-term births was $8.5 \%$ and $28.5 \%$, respectively, compared with $10.6 \%$ and $30.0 \%$ in large municipalities with similar $(50 \%-$ $59 \%$ ) CS rates (figure 4). This suggests that excluding small municipalities from the municipal-level analyses did not lead to bias.

Two initiatives have been recently launched in Brazil with the aim of reducing the negative consequences of scheduled CS. The Federal Medical Council passed a resolution ${ }^{39}$ stating that women have the right to request a CS without medical indications, but that clinicians should wait until the fetus reaches a gestational age of 39 weeks. Unicef launched a media campaign labelled 'quem espera, espera' ('if you are expecting, wait') ${ }^{40}$ to promote the idea that CS should not be carried out before the onset of labour. Whether or not these initiatives will have an impact remains to be seen, as numerous earlier initiatives by government and civil society have so far failed. ${ }^{7}$

Brazil is currently facing a severe political and economic crisis, and the public health and primary education systems are suffering unprecedented cuts. The fact that the health system is, at the same time, producing massive numbers of preterm and early-term newborns who are likely to experience important developmental delays is a reason for enormous concern. Prevention of preterm births requires long-term action against social determinants of health as well as short-term efforts to improve the quality of pregnancy care for poor women, given that coverage is already high. ${ }^{7}$ At the same time, the health system must act to reduce the unacceptably high numbers of CSs that produce hundreds of thousands of early-term and preterm newborns each year. The Ministry of Health has since 2014 being categorising all CS according to Robson's classification, ${ }^{123}$ in an attempt to identify groups where more action is needed to reduce the high CS rates.

From a public health perspective, the larger and more immediate gains may be obtained focusing on primigravidae, for two reasons. First, they account for $40 \%$ of all deliveries in the country. Second, they will not have had a previous CS, and having undergone a previous CS is a common justification for a repeat operation, as the decision between an elective repeat CS and a trial of labour is often difficult. ${ }^{41}$ Lastly, families should be informed that their right to choose for a CS should not compete with the right of their offspring to be delivered after 39 weeks' gestation.

\section{CONCLUSIONS}

The increasing rates of CSs in Brazil, that reached 55.5\% in 2015, have affected the country's gestational age distribution, resulting in rising numbers of preterm and early-term births, and conversely, fewer term infants. We estimate that, in comparison with high-income countries, Brazil has now an annual excess of 354000 births under 39 weeks of gestation. As preterm and early-term children present higher morbidity and are more prone to developmental problems, this represents an important public health problem. This is the first report that quantifies the magnitude of this epidemic, a finding that must be disseminated to health sector workers, policy-makers and the whole society, including young families. The challenge for the near future is to develop and scale up effective interventions to reduce the unacceptable number of CSs without medical indications.

\section{Author affiliations}

${ }^{1}$ Post-Graduate Program in Health and Behavior, Catholic University of Pelotas, Pelotas, Brazil

${ }^{2}$ Ministry of Health, Brasilia, Brazil

${ }^{3}$ Nuffield Department of Obstetrics and Gynaecology and Oxford Maternal and Perinatal Health Institute, Green Templeton College, University of Oxford, Oxford, UK ${ }^{4}$ John Radcliffe Hospital, Oxford, UK

${ }^{5}$ Post Graduate Program in Epidemiology, Universidade Federal de Pelotas, Pelotas, Brazil

${ }^{6}$ Latin American Center for Perinatology, Women and Reproductive Health (CLAP/ WR-PAHO/WHO), Montevideo, Uruguay

Contributors FCB conceived the idea of the present article and together with CGV, formulated the original hypotheses and conducted the analyses of the databases and writing up of the paper. DdLRN, JV, SHK, MFS and JLD-R contributed with original ideas and worked in the drafting of the manuscript, revised and approved the final version. All authors had full access to all of the data (including statistical reports and figures) in the study and can take responsibility for the integrity of the data and the accuracy of the data analysis. Also, all authors agreed to be accountable for all aspects of the work and ensured the manuscript accuracy and integrity.

Funding Brazilian Ministry of Health. 
Disclaimer The funding organisation did not influence the design and conduct of the study; collection, management, analysis or interpretation of the data; and preparation, review or approval of the manuscript; and decision to submit the manuscript for publication

Competing interests None declared.

Patient consent Not required.

Provenance and peer review Not commissioned; externally peer reviewed.

Data sharing statement № additional data are available.

Open access This is an open access article distributed in accordance with the Creative Commons Attribution Non Commercial (CC BY-NC 4.0) license, which permits others to distribute, remix, adapt, build upon this work non-commercially, and license their derivative works on different terms, provided the original work is properly cited, appropriate credit is given, any changes made indicated, and the use is non-commercial. See: http://creativecommons.org/licenses/by-nc/4.0/.

\section{REFERENCES}

1. World Health Organization Human Reproduction Programme. WHO Statement on caesarean section rates. Geneva: Reprod Health Matters, 2015:149-50.

2. Ministério da Saúde, Secretaria de Vigilância em Saúde. As cesarianas no Brasil: situação no ano de 2010, tendência e perspectivas. Saúde Brasil 2011: uma análise da situação de saúde e a vigilância da saúde da mulher. Brasília: Ministério da Saúde, Secretaria de Vigilância em Saúde, 2011:371-94.

3. Betrán AP, Ye J, Moller AB, et al. The increasing trend in caesarean section rates: global, regional and national estimates: 1990-2014. PLoS One 2016;11:e0148343.

4. Silveira MF, Santos IS, Barros AJ, et al. Increase in preterm births in Brazil: review of population-based studies. Rev Saude Publica 2008:42:957-64.

5. Silva AA, Barbieri MA, Bettiol $\mathrm{H}$, et al. Can we explain why Brazilian babies are becoming lighter? Int J Epidemiol 2004;33:821-8.

6. Gomes UA, Silva AA, Bettiol $\mathrm{H}$, et al. Risk factors for the increasing caesarean section rate in Southeast Brazil: a comparison of two birth cohorts, 1978-1979 and 1994. Int J Epidemiol 1999;28:687-94.

7. Victora CG, Aquino EM, do Carmo Leal M, et al. Maternal and child health in Brazil: progress and challenges. Lancet 2011;377:1863-76.

8. Béhague DP, Victora CG, Barros FC. Consumer demand for caesarean sections in Brazil: informed decision making, patient choice, or social inequality? A population based birth cohort study linking ethnographic and epidemiological methods. BMJ 2002;324:942-42.

9. Barros FC, Victora CG, Barros AJ, et al. The challenge of reducing neonatal mortality in middle-income countries: findings from three Brazilian birth cohorts in 1982, 1993, and 2004. Lancet 2005;365:847-54.

10. Leal MC, Esteves-Pereira AP, Nakamura-Pereira M, et al. ProviderInitiated Late Preterm Births in Brazil: Differences between Public and Private Health Services. PLOS One 2016;11:e0155511.

11. ACOG Committee Opinion No 579: Definition of term pregnancy. Obstet Gynecol 2013;122:1139-40.

12. Barros FC, Rossello JL, Matijasevich A, et al. Gestational age at birth and morbidity, mortality, and growth in the first 4 years of life: findings from three birth cohorts in Southern Brazil. BMC Pediatr 2012;12:169.

13. MacKay DF, Smith GCS, Dobbie R, et al. Gestational age at delivery and special educational need: retrospective cohort study of 407,503 schoolchildren. PLoS Med 2011;7:e1000289.

14. Saigal S, Doyle LW. An overview of mortality and sequelae of preterm birth from infancy to adulthood. Lancet 2008;371:261-9.

15. Shapiro-Mendoza CK, Tomashek KM, Kotelchuck M, et al. Effect of late-preterm birth and maternal medical conditions on newborn morbidity risk. Pediatrics 2008;121:e223-e232.

16. Zhang X, Kramer MS. Variations in mortality and morbidity by gestational age among infants born at term. $J$ Pediatr 2009;154:358-62.

17. Altman M, Edstedt Bonamy A-K, Wikström A-K, et al. Cause-specific infant mortality in a population-based Swedish study of term and post-term births: the contribution of gestational age and birth weight. BMJ Open 2012;2:e001152.

18. Ostfeld BM, Schwartz-Soicher O, Reichman NE, et al. Prematurity and Sudden Unexpected Infant Deaths in the United States. Pediatrics 2017;140(1):e20163334.

19. Yang S, Platt RW, Kramer MS. Variation in child cognitive ability by week of gestation among healthy term births. Am J Epidemiol 2010;171:399-406

20. Lindström K, Winbladh B, Haglund B, et al. Preterm infants as young adults: a Swedish national cohort study. Pediatrics 2007;120:70-7.

21. Ananth CV, Joseph KS, Oyelese Y, et al. Trends in preterm birth and perinatal mortality among singletons: United States, 1989 through 2000. Obstet Gynecol 2005;105(Pt 1):1084-91.

22. Kramer MS, Demissie K, Yang $\mathrm{H}$, et al. The contribution of mild and moderate preterm birth to infant mortality. Fetal and Infant Health Study Group of the Canadian Perinatal Surveillance System. JAMA 2000;284:843-9.

23. Saúde Mda. Secretaria de Vigilância em Saúde, Departamento de Vigilância de Doenças e Agravos Não Transmissíveis e Promoção da Saúde. Saúde Brasil 2015/2016: uma análise da situação de saúde e da epidemia pelo vírus Zika e por outras doenças transmitidas pelo Aedes aegypti. Brasilia, DF, Brazil 2017.

24. Kramer MS, Papageorghiou A, Culhane J, et al. Challenges in defining and classifying the preterm birth syndrome. Am J Obstet Gynecol 2012;206:108-12.

25. Andrade CLTde, Szwarcwald CL. Desigualdades sócio-espaciais da adequação das informações de nascimentos e óbitos do Ministério da Saúde, Brasil, 2000-2002. Cadernos de Saúde Pública 2007;23:1207-16.

26. Barros AJ, Hirakata VN. Alternatives for logistic regression in crosssectional studies: an empirical comparison of models that directly estimate the prevalence ratio. BMC Med Res Methodol 2003;3:21.

27. Menacker F, Hamilton BE. Recent trends in cesarean delivery in the United States. NCHS Data Brief 2010;35:1-8.

28. Delnord M, Mortensen L, Hindori-Mohangoo AD, et al. International variations in the gestational age distribution of births: an ecological study in 34 high-income countries. Eur J Public Health 2018;28:303309.

29. Liberatos P, Link BG, Kelsey JL. The measurement of social class in epidemiology. Epidemiol Rev 1988;10:87-121.

30. Barros AJ, Santos IS, Matijasevich A, et al. Patterns of deliveries in a Brazilian birth cohort: almost universal cesarean sections for the better-off. Rev Saude Publica 2011;45:635-43.

31. Delnord M, Blondel B, Prunet C, et al. Are risk factors for preterm and early-term live singleton birth the same? A population-based study in France. BMJ Open 2018;8:e018745.

32. Goldenberg RL, Culhane JF, lams JD, et al. Epidemiology and causes of preterm birth. Lancet 2008;371:75-84.

33. Barros FC, Bhutta ZA, Batra M, et al. Global report on preterm birth and stillbirth (3 of 7): evidence for effectiveness of interventions. BMC Pregnancy Childbirth 2010;10(Suppl 1):S3.

34. Villar J, Valladares E, Wojdyla D, et al. Caesarean delivery rates and pregnancy outcomes: the 2005 WHO global survey on maternal and perinatal health in Latin America. Lancet 2006;367:1819-29.

35. Matijasevich A, Silveira MFda, Matos ACG, et al. Estimativas corrigidas da prevalência de nascimentos pré-termo no Brasil, 2000 a 2011. Epidemiologia e Serviços de Saúde 2013;22:557-64.

36. Silveira MF, Victora CG, Horta BL, et al. Low birthweight and preterm birth: trends and inequalities in four population-based birth cohorts in Pelotas, Brazil, 1982-2015. Int J Epidemiol 2018 (Epub ahead of print).

37. França GV, Restrepo-Méndez MC, Maia MF, et al. Coverage and equity in reproductive and maternal health interventions in Brazil: impressive progress following the implementation of the Unified Health System. Int J Equity Health 2016;15:149.

38. Kramer MS. Socioeconomic disparities in preterm birth. Paediatr Perinat Epidemiol 2015;29:169-71.

39. Conselho Federal de Medicina. Conselho Federal de Medicina. Resolucão CFM No 2.144/2016. Brasilia: CFM, 2016.

40. UNICEF (United Nations Children's Fund). Quem espera espera. Brasilia: UNICEF, 2017.

41. Kok N, Ruiter L, Lindeboom R, et al. Elective repeat cesarean delivery compared with trial of labor after a prior cesarean delivery: a propensity score analysis. Eur J Obstet Gynecol Reprod Biol 2015;195:214-8. 